\title{
PHYTOCHEMICAL SCREENING AND ANTIMICROBIAL ASSAY OF SOME NEPALESE MEDICINAL PLANTS
}

\author{
Bijaya Laxmi Maharjan*, Smriti Mainali** and Bikash Baral* \\ * Nepal Academy of Science and Technology, Kathmandu, Nepal. \\ **Central Department of Microbiology, Tribhuvan University, Kathmandu, Nepal.
}

\begin{abstract}
Medicinal plants constitute several bioactive compounds that are antimicrobial. Due to the extensive need of the new antimicrobial compounds of plant origin the study was conducted. The present paper deals with the qualitative phytochemical analysis and antimicrobial assay of methanolic extracts of four medicinal plants namely Butea monosperma (seed), Cissampelos pareira (root), Myrica esculenta (bark) and Selinum tenuifolium (root). The standard phytochemical test of the extracts revealed the presence of polyphenols, glycosides and coumarins in all the plant extracts. For the in-vitro antimicrobial assay, agar well diffusion method was employed against human pathogenic bacteria (11) and phytopathogenic fungi (5). The extracts of C. pareira, M. esculenta were effective against all the tested bacteria and fungi which indicated their broad spectrum antimicrobial potential. The extract of B. monosperma was effective against B. subtilis, S. typhi, Acinetobacter species, F. oxysporum, F. moniliformie, E. turticum and S. roulfsii. But the extract of S. tenuifolium was ineffective against all the tested bacteria but was effective against all the fungal strains revealing it to have more antifungal potential. The antimicrobial properties of these plant extracts may be due to the presence of various secondary metabolites. The results provided evidence that the studied plants might indeed be employed in the management of microbial infections.
\end{abstract}

Key words: Plant extract; Phytochemicals; Antibacterial; Antifungal.

\section{INTRODUCTION}

In recent years, antimicrobials derived from the plants have been receiving increasing attention as synthetic antibiotics have shown ineffectiveness against several pathogenic organisms due to increasing drug resistance (Akgul and Saglikoglu, 2005). Also, the incessant and indiscriminate application of the chemical pesticides for quick and effective management of plant diseases and microbial contamination in several agricultural commodities has caused health hazards due to their residual toxicity and development of resistance by many pathogenic organisms and pests against these chemicals (Satish et al, 1998).

There is an urgent need for alternative agents for the management of pathogenic microorganisms. Research on new antimicrobial substances must therefore be continued and all possible strategies should be explored (Shrestha et al, 2009). Reports are available on the use of several plant byproducts which possess antimicrobial properties on several pathogenic bacteria and fungi.

Medicinal plants are known to owe their curative potentials to certain biological active substances which exist in different parts of plant. The chemicals which are referred to as active principles or phytochemical substances include terpenes, flavonoid, bioflavonoid, bezophenones, xanthones as well as some metabolites such as tannins, saponins, cyanates, oxalate and anthra-quinones (Hena et al, 2010).

The resistance acquired by microbes to the existing antibiotics calls for increased efforts in the development of new antibiotics. Although a number of plants with antimicrobial potential have been identified, great number still remains unidentified. Great range of bioclimatic variation from tropical to alpine brings richness in biological diversity in Nepal. Many kinds of plants are prevalent in this country and a large number of them have been used for antimicrobial assay (Watanabe et al, 2005). There is a dire need of extensive studies of medicinal plants found in Nepal with a special reference to their properties to fight against diseases. Therefore, antimicrobial properties of some medicinal plants found in Nepal were screened.

\section{MATERIALS AND METHODS}

\section{Plant materials collection}

The parts of four different plants i.e. Butea monosperma (Lam) Kuntze (seed), Cissampelos pareira L. (root), Myrica esculenta Buch-Ham. Ex D. Don (bark) and Selinum tenuifolium Wall (root) were used in the study. These plant

Author for Correspondence: Maharjan Bijaya Laxmi, Natural Products Research Laboratory, Nepal Academy of Science and Technology. Email: utpalbodhi@gmail.com 
materials were air dried and grinded to powder.

\section{Preparation of extracts}

The methanolic extract of each powdered plant materials were prepared by Soxhlet extraction method and the solvent was removed using Rotary Vaccum Evaporator. The extracts obtained were stored at $4^{\circ} \mathrm{C}$. The working solution of each plant extracts was prepared in dimethyl sulfoxide (DMSO) so as to get the final concentration of $100 \mathrm{mg} / \mathrm{ml}$.

\section{Phytochemical screening}

Standard phytochemical screening test was carried out on the plant samples using method of Trease and Evans (1989) to determine the presence of polyphenols, alkaloids, glycosides, quinines, anthocyanosides, anthracyanosides, flavonic glycosides, coumarins, etc.

\section{Microbial strains and standard inoculum preparation}

The bacterial strains used for antibacterial assay were Bacillus subtilis, Staphylococcus aureus, Escherichia coli, Salmonella typhi, Salmonella paratyphi, Pseudomonas aeruginosa, Enterococcus faecalis, Schigella species, Acinetobacter species, Proteus mirabilis and Klebsiella pneumoniae. The inoculums size of each bacterial strain comparable to O.5 Mc Farland standard (1.5 x 10 $\mathrm{CFU} / \mathrm{ml})$ was prepared in Nutrient broth medium. For the antifungal assay, Fusarium oxysporum, F. moniliformie, F. proliferatum, Exserohilum turticum and Sclerotium rolfsii were used. The inoculums size of each fungal strain was prepared in Potato Dextrose Broth and adjusted to a range of $1 \times 10^{6}-5 \times 10^{6}$ spores/ ml (Aberkene et al., 2002) .

\section{Screening for antimicrobial susceptibility}

Agar well diffusion method was employed to assay the plant extracts for antimicrobial activity. Mueller Hinton Agar and Potato Dextrose Agar were used for the antibacterial and antifungal susceptibility testing respectively. The standard culture inoculum of each organisms prepared were then spread on respective media plates using sterile swabs. The wells were made on the media with the help of sterile cork borer ( $6 \mathrm{~mm}$ diameter). Then, $50 \mu \mathrm{l}$ of plant extracts were loaded on the wells and allowed to diffuse into media. Also, a control was run parallel for each microbial culture using DMSO that was used as solvent for preparation of working solution of extracts. The plates were incubated at $37^{\circ} \mathrm{C}$ for $24 \mathrm{hrs}$ for bacterial culture and at $27^{\circ} \mathrm{C}$ for 5 days for fungal culture. Zone of inhibition (ZOI) was measured using a meter scale and the mean value was recorded (in $\mathrm{mm}$ ) as described by Mukhrejee et al (1995). All studies were performed in triplicate and finally the mean value was recorded.

\section{RESULTS}

The preliminary phytochemical screening indicated the presence of polyphenols, glycosides and coumarins but the alkaloids and anthoquinones were absent in all the plant extracts as shown in table 1 .

The extracts of $C$. pareira, $M$. esculenta were effective against all the tested bacteria and fungi. The extract of B. monosperma
Table 1: Qualitative phytochemical screening of methanolic plant extracts

\begin{tabular}{|l|c|c|c|c|}
\hline Phytochemicals & B. monosperma & C. pareira & M. esculenta & S. tenuifolium \\
\hline Polyphenols & + & + & + & + \\
\hline Red compound & - & - & + & - \\
\hline Alkaloids & - & - & - & - \\
\hline Glycosides & + & + & + & + \\
\hline Quinones & + & + & + & + \\
\hline Anthocyanosides & - & - & - & - \\
\hline Anthracyanosides & + & - & + & + \\
\hline Flavonic glycosides & + & + & - & + \\
\hline Coumarins & + & + & + & + \\
\hline
\end{tabular}

Table 2: Screening of antibacterial assay of the methanolic plant extracts

\begin{tabular}{|l|c|c|c|c|}
\hline \multirow{2}{*}{ Bacterial strains tested } & \multicolumn{5}{|c|}{ Diameter of ZOI $(\mathrm{mm})$ given by plant extracts used } \\
\cline { 2 - 5 } & B. monosperma & C. pareira & M. esculenta & S. tenuifolium \\
\hline Bacillus subtilis & 9 & 9 & 11 & - \\
\hline Staphylococcus aureus & - & 8 & 11 & - \\
\hline Escherichia coli & - & 8 & 10 & - \\
\hline Salmonella typhi & 7 & 7 & 8 & - \\
\hline Salmonella paratyphi & - & 7 & 8 & - \\
\hline Psendomonas aeruginosa & - & 7 & 12 & - \\
\hline Enterococcus faecalis & - & 8 & 9 & - \\
\hline Schigella species & - & 8 & 10 & - \\
\hline Acinetobacter species & 7 & 8 & 10 & - \\
\hline Proteus mirabilis & - & 7 & 9 & - \\
\hline Klebsiella pneumoniae & - & 7 & 11 & - \\
\hline
\end{tabular}

Values are means of three replicates

Table 3: Screening of antifungal assay of the methanolic plant extracts

\begin{tabular}{|l|c|c|c|c|}
\hline \multirow{2}{*}{ Fungal strains tested } & \multicolumn{5}{|c|}{ Diameter of ZOI (mm) given by plant extracts used } \\
\cline { 2 - 5 } & B. monosperma & C. pareira & $\begin{array}{l}\text { M. } \\
\text { esculenta }\end{array}$ & S. tenuifolium \\
\hline F. oxysporum & 10 & 14 & 12 & 12 \\
\hline F. moniliforme & 8 & 16 & 11 & 11 \\
\hline F. proliferatum & - & 10 & 12 & 11 \\
\hline Exserohilum turticum & 9 & 11 & 11 & 10 \\
\hline Sclerotium rolfsii & 10 & 11 & 12 & 10 \\
\hline
\end{tabular}

Values are means of three replicates

was effective against B. subtilis, S. typhi, Acinetobacter species, F. oxysporum, F. moniliforme, E. turticum and $S$. rolfsii. But the extract of $S$. tenuifolium was ineffective against all the tested bacteria but was effective against all the fungal strains (table 2 \& 3).

\section{DISCUSSION AND CONCLUSION}

The antimicrobial properties of plants are perhaps due to the presence of various secondary metabolites. Coumarins, present in all the studied plants, are reported to possess antimicrobial activity (Soine, 1964).

The different plant extracts showed the variation in the antibacterial and antifungal activity. According to Gonzalez et al. (1994) the optimal effectiveness of medicinal plants may not be due to one main active constituent but to the combined action of different compounds originally present in the plant.

Plants are important source of potentially useful structures for the development of new antimicrobial agents. The first step toward this goal is the in-vitro antimicrobial activity assay. The plants used in the study are reported to have the good antimicrobial properties (Thatoi et al, 2008; Biswas et al, 2009; Bafna and Mishra, 2010; Sindhia VR and Bairwa, 2010).

Plant extracts have great potential as antimicrobial compounds against microorganisms. The plants used in the 
study were found to have antibacterial and antifungal property although the strength of their action varied upon different microbial strains. Thus, they can be used against these microbes. Also, the identification of the bioactive compound against these microbes is quite essential. If the active ingredients of the extracts are isolated and possibly crystallized, therapeutic antibiotics could be produced from these compounds.

\section{ACKNOWLEDGEMENTS}

The authors would like to thank Ms. Hasina Karki for her help during the entire research work period.

\section{REFERENCES}

Aberkene, A., Cuenca-Estrella, M., A. Gomez-Lopez, E., Petrikkou, E., Mellado, A., Monzon, J.L., Rodriguez-Tudela and the Eurofung Network. 2002. Comparative evaluation of two different methods of inoculum preparation for antifungal susceptibility testing of filamentous fungi. Journal of Antimicrobial Chemotherapy. 50(5):719-722.

Akgul, C. and Saglikoglu, G. 2005. Antibacterial activity of crude methanolic extract and its fractions of aerial parts of Anthemis tinctoria. Indian Journal of Biochemistry and Biophysics. 42: 395-397.

Bafnia, A. and Mishra, S. 2010. Antioxidant and immunomodulatory activity of the alkaloidal fraction of Cissampelos pareira Linn. Scientia Pharmaceutica. 78: 21-31.

Biswas, P., Bhattacharyya, A., Bose, .PC., Mukherjee, N. and Aditayachaudhury, N. Further studies on the sensitivity of plant pathogenic microorganisms towards some naturally occurring chalcones and flavanones. Cellular and Molecular life sciences. 37(4): 397-398.
Gonzalez, A., Moujir, G., Bazzocchi, I., Correa, I.L. and Guptha, M.D. 1994. Screening of antimicrobial and cytotoxic activities of Panamanian plants. Phytomedicine. 1: 149-153.

Hena, J.S., Adamu, A.K., Iortsuun, D.N. and Olonitola, O.S. 2010. Pytochemical screening and antimicrobial effect of the aqueous and methanolic extracts of roots of Balanites aegyptiaca (Del.) on some bacteria species. Science World Journal. 5(2): 59-62.

Mukhrejee, P.K., Balsubramanian, R., Saha, K., Pal, M. and Saha, B.P. 1995. Antibacterial efficiency of Nelumbo nucifera Nymphaeceae rhizome extract. Indian drugs. 32: 274-276.

Satish, S., Raveesha, K.A. and Janardhana, G.R. 1998. Letters in Applied Microbiology. 28: 145-147.

Shrestha, P.R., Sharma, S., Giri, R.K. and Karki, H. 2009. Antibacterial activity of medicinal plant extracts. Plant resources. 31: 51-55.

Sindhia, V.R. and Bairwa, R. 2010. Plant review: Butea monosperma. International Journal of Pharmaceutical and Clinical Research. 2(2): 90-94.

Soine, T.O. 1964. Naturally occurring coumarins and related physiological activitirs. Journal of Pharmaceutical Science. 53: 231-264.

Thatoi, H.N., Panda, S.H., Rath, S.K. and Dutta, S.K. 2008. Antimicrobial activity and ethnomedicinal uses of some medicinal plants from Similipal biosphere reserve, Orissa. Asian Journal of Plant Sciences. 7(3): 260-267.

Trease, G.E. and Evans, W.C. 1989. A textbook of Pharmacology, Ed. Ballieria T.nal Ltd. London.

Watanabe, T., Rajbhandari, K.R., Malla, K.J. and Yahara, S. 2005. A handbook of medicinal plants of Nepal. Kobfai Publishing Project, Bangkok, Thailand. 